\title{
IDENTIFIKASI DAN KEANEKARAGAMAN JENIS SERANGGA DI HUTAN KOTA BUNGKIRIT KABUPATEN KUNINGAN JAWA BARAT
}

\author{
Faizal Muhamad Fasa' ${ }^{1)}$, Ilham Adhya ${ }^{2)}$, Nurdin ${ }^{3)}$ \\ ${ }^{1}$ Program Studi Kehutanan, Fakultas Kehutanan, Universitas Kuningan \\ email: faizal02@gmail.com \\ ${ }^{2}$ Pragram Studi Kehutanan, Fakultas Kehutanan, Universitas Kuningan \\ email: ilham.adhya@uniku.ac.id \\ ${ }^{3}$ Program Studi Kehutanan, Fakultas Kehutanan, Universitas Kuningan \\ email: nurdin@uniku.ac.id
}

\begin{abstract}
Abstrak. Serangga atau insekta merupakan kelompok dari hewan beruas arthopoda yang berkaki enam. Sehingga ditemukan hampir disemua ekosistem, semakin banyak tempat dengan berbagai penggolongan jenis serangga berdasarkan aktivitasnya dikenal serangga yang aktif di siang hari dan serangga yang aktif di malam hari. Keberadaan jenis serangga di hutan bungkirit sangat penting karena hutan kota bungkirit memiliki fungsi sebagai area lingkungan yang menjaga ekosistem dan keanekaragaman hayati di Kota Kuningan serta memiliki fungsi sebagai sumber daya alam yang sangat tinggi berupa Flora Dan Fauna. Tujuan dari penelitian ini untuk mengidentifikasi jenis serangga di areal hutan kota bungkirit Kabupaten Kuningan dan untuk mengetahui tingkat keanekaragaman jenis serangga yang terdapat di areal Hutan Kota Bungkirit Kabupaten Kuningan. Penetian ini dilakukan dengan menggunakan metode Sweep Net dan Light Trap. Hasil penelitian menunjukkan terdapat 14 jenis serangga, nilai indeks keanekaragamannya ( $\left.H^{\prime}\right)$ adalah 2,31, indeks kemerataan pada lokasi sawah 0,90 mendapat nilai tertinggi sedangkan pada lokasi hutan campuran terdapat 0,88. Hasil perhitungan indeks sorenson mengetahui kesamaan jenis serangga pada lokasi penelitian sawah dan hutan campuran ditunjukkan dengan adanya kesamaan setiap lokasi penelitian sebesar 31\% (sedang).
\end{abstract}

Kata Kunci: Serangga, Hutan Kota, Sweep Net, Light Trap.

\section{PENDAHULUAN}

Serangga sebagai salah satu komponen keanekaragaman hayati memiliki peranan penting dalam jaring makanan yaitu sebagai herbivora atau serangga pemakan tumbuhan, karnivora atau serangga pemakan hewan atau pemakan serangga lainnya, dan pemakan bangkai atau detrivor (Strong et al. 1984 dalam Rizali et al, 2002).Di samping itu terdapat fungsi lain dari serangga yaitu sebagai organisme yang memiliki sensitifitas terhadap kondisi lingkungan atau bioindikator. Jenis serangga ini mulai banyak diteliti karena bermanfaat untuk mengetahui kondisi kesehatan suatu ekosistem. Tidak adanya serangga menandakan lingkungan tersebut telah tercemar, karena serangga ini tidak dapat hidup pada habitat yang sudah tercemar (Samways 1994 dalam Rizali et al, 2002).

Hutan Kota Bungkirit adalah salah satu Hutan Kota di Kabupaten Kuningan yang memiliki luas 1,5 ha. Di kawasan hutan kota bungkirit terdapat area sawah, dan area hutan campuran.

Keberadaan jenis serangga di Hutan Kota Bungkirit sangat penting, merujuk pada pemaparan sebelumnya yaitu Hutan Kota Bungkirit memiliki fungsi sebagai area lingkungan yang menjaga ekosistem dan keanekaragaman hayati di Kota Kuningan serta memiliki fungsi sebagai sumber daya alam yang sangat tinggi berupa flora dan fauna. Oleh karena itu, penelitian terhadap jenis serangga di Hutan Kota Bungkirit perlu dilakukan.

\section{METODOLOGI PENELITIAN}

Penelitian dilaksanakan selama satu bulan, yaitu pada bulan September 2018 di Hutan Kota Bungkirit Kabupaten Kuningan.

Alat yang digunakan dalam penelitian ini yaitu Light trap ini yaitu lampu, corong dan kantung plastik (baskom), serta rangka beratap, sweep net, kamera digital. Sedangkan bahan yang digunakan yaitu serangga yang ada di Hutan Kota Bungkirit.

Pengambilan sampel dilaksanakan sebanyak 7 kali ulangan (siang dan malam) pada setiap plot pengamatan (3 plot di sawah dan hutan campuran) . Untuk serangga siang pengambilan data dimulai dari jam 07.00 - 15.00 dengan menggunakan jaring serangga darat (Sweep net). 
Penggunaan metode ini dilakukan dengan cara menyapukan jaring kepada tumbuhan seperti semak dan rumput agar bisa dibandingkan dengan pengamatan pada tempat lain atau pada pengamatan berikutnya, penggunaan metode ini harus di standarisasi. Strandarisasi dilakukan diantaranya dengan cara menyapukan ke arah depan dan belakang, misalnya masing - masing 10 sampai 20 kali sapuan, setelah itu baru dilakukan pengumpulan terhadap serangga yang tertangkap dalam jaring serangga.

Untuk serangga malam pengambilan data dimulai dari jam 18.00 - 05.00. Pengambilan sampel serangga dilakukan dengan cara memasang Light Trap. Prinsip kerja perangkap ini cukup sederhana yaitu dengan menarik serangga - serangga tersebut mengerubunginya, mereka akan berputar - putar kemudian masuk pada perangkap yang terpasang.

Analisisi data yang dipergunakan diantaranya:

\section{a. Frekuensi Mutlak}

Frekuensi Mutlak (FM) suatu jenis serangga.Frekuensi mutlak menunjukkan jumlah individu serangga tertentu yang ditemukan pada habitat yang dinyatakan secara mutlak(Suin, 1997).

$$
\mathrm{FM}=\frac{\text { Jumlah ditemukan }}{\text { suatu jenis serangga }}
$$

\section{b. Frekuensi Relatif}

Frekuensi Relatif (FR) suatu jenis serangga

$$
\mathrm{FR}=\frac{\mathrm{FM}}{\sum \mathrm{FM}} \times 100 \%
$$

Frekuensi Relatif menujukan yang lebih sering hadir suatu jenis serangga pada habitat dan dapat menggambarkan penyebaran jenis serangga tersebut (Suin, 1997).

c. Kerapatan Mutlak

Kerapatan Mutlak menunjukkan jumlah serangga yang ditemukan pada habitat yang dinyatakan secara mutlak (Suin, 1997)

$$
\text { Jumlah individu jenis }
$$

$$
\mathrm{KM}=\frac{\text { yang tertangkap }}{\text { Jumlah penangkapan }}
$$

\section{d. Kerapatan Relatif}

Kerapatan Relatif (KR) suatu jenis serangga

$$
\mathrm{KR}=\frac{K M}{\sum K M} \times 100 \%
$$

\section{e. Indeks Keragaman}

Untuk mengetahui indeks keanekaragaman digunakan rumus Shannon-Wienner $\mathrm{H}^{\prime}$ dengan rumus :

$$
\begin{gathered}
\mathrm{H}^{\prime}=-\sum \text { pi ln pi } \\
\mathrm{Pi}=\frac{\mathrm{ni}}{\mathrm{N}}
\end{gathered}
$$

Keterangan :

$\mathrm{H}^{\prime}=$ indeks keanekaragaman.

$\mathrm{Pi}=$ perbandingan jumlah individu suatu jenis dengan keseluruhan jenis.

$\mathrm{ni}=$ jumlah jenis yang tertangkap.

$\mathrm{N}=$ jumlah total individu semua jenis.

Dengan kriteria indeks keanekaragaman menurut Michael (1995) adalah sebagai berikut:

Jika $\mathrm{H}^{\prime}<1$ berarti keanekaragaman serangga rendah

Jika H'1-3 berarti keanekaragaman serangga sedang

Jika > 3 berarti keanekaragaman serangga tinggi.

\section{f. Indeks Kemerataan}

Keanekaragaman tidak terlepas dari kemerataan, yang dapat dihitung dengan formulasi (Ludwig dan Reynold, 1998) yaitu:

\section{Keterangan :}

$$
\mathrm{E}=\frac{\mathrm{H}^{\prime}}{\operatorname{In} \mathrm{S}}
$$

$\mathrm{H}^{\prime}=$ Indeks keanekaragaman Shannon Wienner

$\mathrm{S}=$ Jumlah jenis serangga

Semakin kecil nilai E, berarti semakin sempit penyebaran jenis dan semakin besar nilai E, bearti semakin luar penyebaran jenis.Kriteria Kemerataannya :

- Jika $\mathrm{E}=<0.3$ menunjukkan kemerataan jenis tergolong rendah

- Jika $\mathrm{E}=0.3-0.6$ kemerataan jenis tergolong sedang

- Jika $\mathrm{E}=>0.6$ maka kemerataan jenis tergolong tinggi

Semakin beragam suatu habitat keanekaragaman semakin merata (Magurran, 1998).

\section{g. Indeks Kesamaan}

Untuk mengetahui kesamaan serangga di ke empat lokasi penelitian, digunakan rumus Indeks kesamaan Sorensen (Odum, 1997): 
Keterangan :

$$
\text { IS }=\frac{2 j}{a+b}
$$

IS = Indeks Kesamaan

$\mathrm{j}=$ jumlah jenis serangga yang sama yang ditemukan di ke-dua lokasi

$\mathrm{a}=$ jumlah serangga yang ditemukan dilokasi a

$\mathrm{b}=$ jumlah serangga yang ditemukan dilokasi b

Dengan kriteria indeks kesamaan Sorensen sebagai berikut :
Jika $\mathrm{S}>50 \%$ maka pada daerah tersebut memiliki kesamaan

Jika $\mathrm{S}<50 \%$ maka pada daerah tersebut tidak memiliki kesamaan.

\section{HASIL DAN PEMBAHASAN}

\section{Jumlah Individu Serangga}

Berdasarkan penelitian di dapatkan 14 jenis serangga pada dua tipe habitat yaitu tipe habitat Sawah dan tipe habitat Hutan campuran. Dijumpai berbagai jenis serangga seperti yang disajikan pada diagram dan tabel di bawah ini :

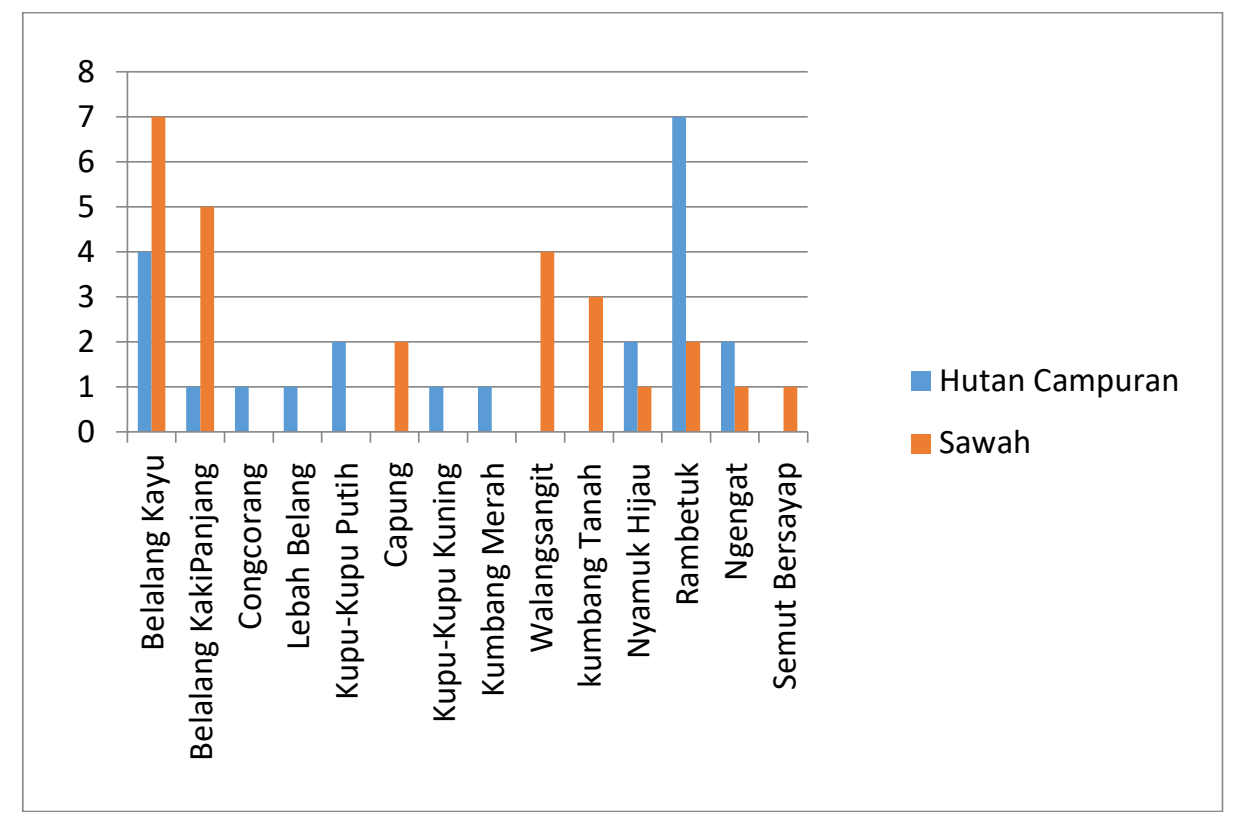

Gambar 1 Jenis Dan Jumlah Individu Serangga

Tabel 1. Serangga Hutan Kota Bungkirit

\begin{tabular}{|c|c|c|c|c|}
\hline \multicolumn{5}{|c|}{ Hutan Kota Bungkirit } \\
\hline \multicolumn{5}{|c|}{ Siang } \\
\hline Plot & No & Nama Lokal & Nama IImiah & Jumlah \\
\hline \multirow[t]{3}{*}{1} & 1 & Belalang Kayu & Phlaeoba Fomosa & 4 \\
\hline & 2 & Congcorang & Mantis Religiosa & 1 \\
\hline & 3 & Lebah belang & Polistes $S p$ & 1 \\
\hline \multirow[t]{2}{*}{2} & 1 & Kupu - Kupu Putih & Leptosia Nina clorograpah & 1 \\
\hline & 2 & $\begin{array}{l}\text { Belalang } \\
\text { panjang }\end{array}$ & Euscyrtus Hemelytrus & 1 \\
\hline \multirow[t]{3}{*}{3} & 1 & Kupu-Kupu Kuning & EureumaSari Sari & 1 \\
\hline & 2 & Kupu-kupu putih & Leptosia Nina Cholograpah & 1 \\
\hline & 3 & Kumbang merah & Epilacna $S p$ & 1 \\
\hline \multicolumn{5}{|c|}{ Malam } \\
\hline 1 & 1 & Rambetuk & Drosophila Melanogaster & 2 \\
\hline
\end{tabular}




\begin{tabular}{rrlrr} 
& 2 & Ngengat & Euproctis Chrysorrhoea & 1 \\
2 & 1 & Nyamuk Hijau & Chironomidae & 1 \\
& 2 & Ngengat & Euproctis Chrysorrhoea & 1 \\
& 3 & Rambetuk & Drosophila Melanogaster & 3 \\
3 & 1 & Rambetuk & Drosophila Melanogaster & 2 \\
& 2 & Nyamuk Hijau & Lhironomidae & 1 \\
\hline
\end{tabular}

Tabel 2. Serangga Lahan Sawah

\begin{tabular}{|c|c|c|c|c|}
\hline \multicolumn{5}{|c|}{ Sawah } \\
\hline \multicolumn{5}{|c|}{ Siang } \\
\hline Plot & No & Nama Lokal & Nama Ilmiah & Jumlah \\
\hline \multirow[t]{2}{*}{1} & 1 & Belalang Kayu & Phlaeoba Fomosa & 2 \\
\hline & 2 & Belakang kaki panjang & Euscyrtus Hemelytrus & 1 \\
\hline \multirow[t]{3}{*}{2} & 1 & Capung & Orthetrum Sabina & 2 \\
\hline & 2 & Belalang kaki panjang & Euscyrtus Hemelytrus & 3 \\
\hline & 3 & Belalang Kayu & Phlaeoba Fomosa & 2 \\
\hline \multirow[t]{4}{*}{3} & 1 & Welang Sangit & Leptocorisa Acuta & 1 \\
\hline & 2 & Belalang Kayu & Phlaeoba Fomosa & 3 \\
\hline & 3 & Belalang kaki panjang & Euscyrtus Hemelytrus & 2 \\
\hline & 4 & Capung & Orthetrum Sabina & 1 \\
\hline \multicolumn{5}{|c|}{ Malam } \\
\hline \multirow[t]{3}{*}{1} & 1 & Kumbang tanah & Harpalus Herbivagus & 1 \\
\hline & 2 & Kungkang & Leptocorisa Acuta & 1 \\
\hline & 3 & Nyamuk Hijau & Chironomidae & 1 \\
\hline \multirow[t]{3}{*}{2} & 1 & Kumbang tanah & Harpalus Herbivagus & 2 \\
\hline & 2 & Belalang kaki panjang & Euscyrtus Hemelytrus & 1 \\
\hline & 3 & Semut bersayap & Oecophylla & 1 \\
\hline \multirow[t]{3}{*}{3} & 1 & Rambetuk & Drosophila Melanogaster & 2 \\
\hline & 2 & Walang Sangit & Leptocorisa Acuta & 1 \\
\hline & 3 & Ngengat & Euproctis Chrysorrhoea & 1 \\
\hline
\end{tabular}

Berdasarkan tabel diatas hasil menunjukkan jumlah serangga yang tertangkap dengan menggunakan perangkap jenis light trap pada lokasi penelitian (sawah) di Hutan Kota Bungkirit adalah sebanyak 9 ordo, yang terdiri 6 family dengan jumlah populasi serangga sebanyak 26. Sedangkan pada lokasi penelitian (hutan campuran) di Hutan Kota Bungkirit adalah sebanyak 7 ordo, yang terdiri 6 family dengan jumlah populasi serangga sebanyak 22 jenis.

Jenis serangga yang dominan yaitu Melanoplus differentialis dengan total 9 Individu. Sementara serangga yang tidak dominan yaitu Mantis Religiosa, Polistes Sp, Eurema Sari Sari, coccinellidae dan Polyrhachis Baltomi Dengan masing - masing srangga didapat 1 individu.

Tabel 3. Populasi Serangga di Dua Tipe Habitat
Pada habitat sawah jenis keanekaragamannya lebih sedikit dibandingkan hutan campuran, hal ini di karenakan terdapat aktivitas manusia yang mengolah sawah, kondisi tersebut sesuai dengan penelitian diperkuat menurut (Philott dan Armbrecht, 2006) jenis serangga di sawah lebih rentan karena adanya pemberian pupuk dan penggunaan inteksida.

Keanekaragaman yang tinggi terjadi di habitat hutan campuran, jumlah jenis dan keanekaragaman hal ni karena tipe habtat di hutan campuran memiliki keanekaragaman yang tinggi,sehingga jenis serangga yang ada mendapat makanan sebagai kelangsungan hidup serangga

tersebut. 


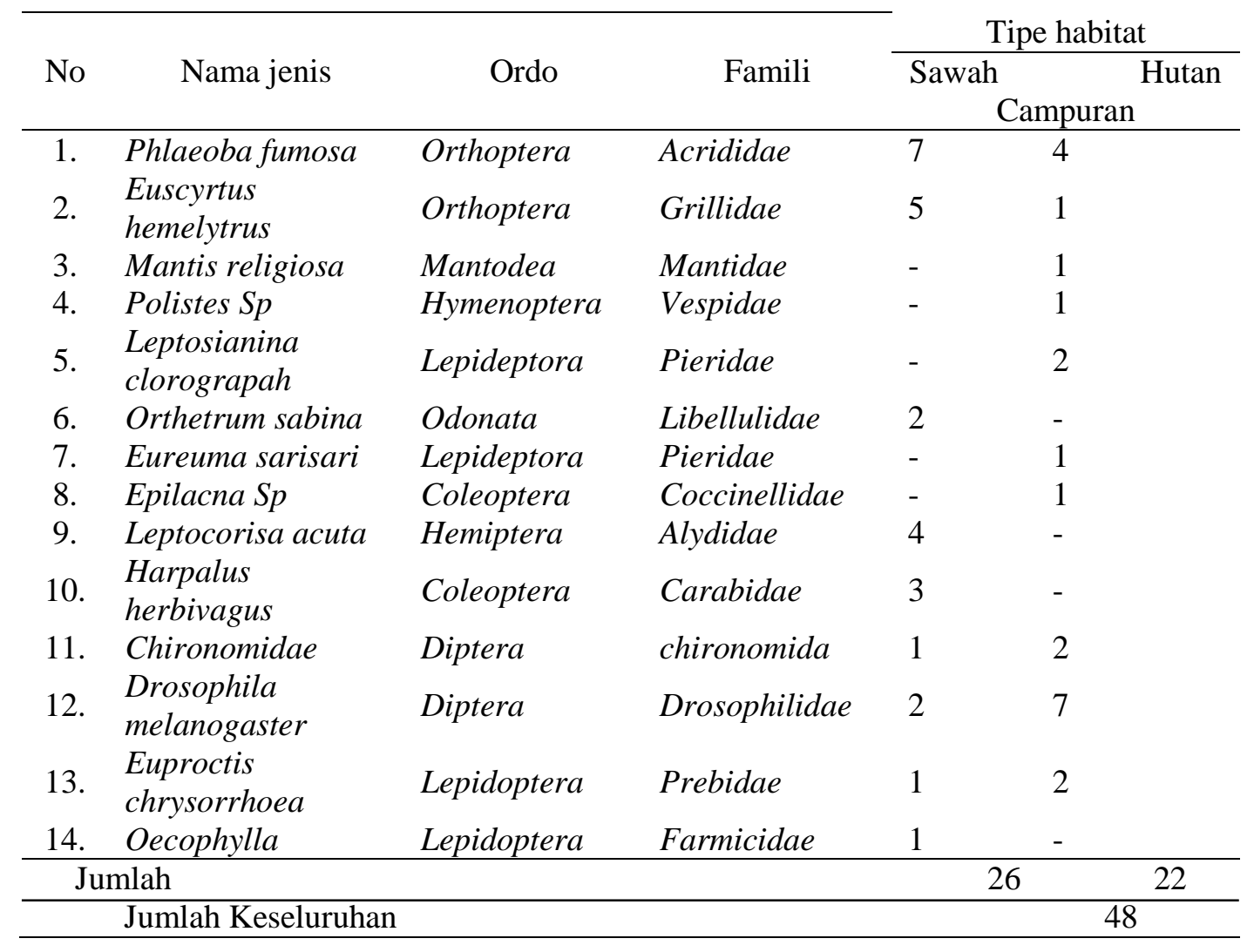

\section{Frekuensi}

Nilai frekuensi mutlak, frekuensi relatif, kerapatan mutlak dan kerapatan relatif dari serangga yang tertangkap oleh perangkap light trap pada lokasi sawah dan hutan campuran di lingkungan hutan kota bungkirit dapat dilihat pada tabel di bawah ini.

Tabel 4. Nilai Frekuensi Mutlak, Frekuensi Relatif, Kerapatan Mutlak dan Kerapatan Relatif

\begin{tabular}{|c|c|c|c|c|c|c|c|}
\hline No & Nama Jenis & Ordo & Family & FM & $\begin{array}{l}\text { FR } \\
(\%)\end{array}$ & KM & $\begin{array}{l}\mathrm{KR} \\
(\%)\end{array}$ \\
\hline 1. & $\begin{array}{l}\text { Belalang } \\
\text { Kayu }\end{array}$ & Orthoptera & Acrididae & 1.57 & 9.42 & 5.50 & 21.1 \\
\hline 2. & $\begin{array}{l}\text { Belalang kaki } \\
\text { panjang }\end{array}$ & Orthoptera & Grillidae & 0.85 & 5.14 & 3.00 & 11.5 \\
\hline 3. & Congcorang & Mantodea & Mantidae & 0.14 & 0.85 & 1.00 & 3.84 \\
\hline 4. & Lebah Belang & Hymenoptera & Vespidae & 0.14 & 0.85 & 0.50 & 2,27 \\
\hline 5. & $\begin{array}{l}\text { Kupu - kupu } \\
\text { putih }\end{array}$ & Lepideptora & Pieridae & 0.28 & 1.71 & 1.00 & 4.54 \\
\hline 6. & Capung & Odonata & Libellulidae & 0.28 & 1.71 & 1.00 & 3.84 \\
\hline 7. & $\begin{array}{l}\text { Kupu - kupu } \\
\text { kuning }\end{array}$ & Lepideptora & Pieridae & 0.14 & 0.85 & 0.50 & 2.27 \\
\hline 8. & $\begin{array}{l}\text { Kumbang } \\
\text { merah }\end{array}$ & Coleoptera & Coccinellidae & 0.14 & 0.85 & 0.50 & 2.27 \\
\hline 9. & Kungkang & Hemiptera & Alydidae & 0.57 & 3.42 & 0.50 & 1.92 \\
\hline 10. & $\begin{array}{l}\text { Kumbang } \\
\text { tanah }\end{array}$ & Coleoptera & Carabidae & 0.42 & 2.57 & 1.00 & 3.84 \\
\hline 11. & $\begin{array}{l}\text { Nyamuk } \\
\text { Hijau }\end{array}$ & Diptera & chironomida & 0.42 & 2.57 & 1.00 & 6.81 \\
\hline 12. & Rambetuk & Diptera & Drosophilidae & 1.28 & 7.71 & 4.50 & 20.4 \\
\hline 13. & Ngengat & Lepidoptera & Prebidae & 0.42 & 2.57 & 1.50 & 6.81 \\
\hline 14. & Semut & Lepidoptera & Farmicidae & 0.42 & 0.85 & 0.50 & 1.92 \\
\hline
\end{tabular}


Pada tabel 4 bahwa nilai frekuensi mutlak yang tertinggi pada habitat sawah yaitu serangga Phlaeoba Fumosa yaitu 1,57 yang sebanyak 7 ekor dengan frekuensi relatif sebesar 9,42\%. Hal ini disebabkan karena jumlah serangga yang diperoleh pada penelitian lebih banyak atau lebih tinggi dari jumlah serangga yang lain. Sedangkan nilai frekuensi mutlak terendah terdapat pada serangga Chironomidae, Euproctis Chrysorrhoea dan Oecophylla yaitu sebanyak 1 ekor dengan frekuensi relatif sebesar $0,14 \%$. Sedangkan pada hutan campuran nilai frekuensi mutlak yang tertinggi terdapat pada serangga Drosophilia Melanogaster yaitu 1,28 yang sebanyak 7 ekor dengan frekuensi relatif sebesar 7,71 \%. Hal ini disebabkan karena jumlah serangga yang diperoleh pada penelitian lebih banyak atau lebih tinggi dari jumlah serangga yang lain. Sedangkan nilai frekuensi mutlak terendah terdapat pada serangga Euscyrtus Hemelytrus, Mantis Religiosa,
Polistes Sp, Eurema Sari Sari dan Epilacna Sp yaitu sebanyak 1 ekor dengan frekuensi relatif sebesar $0,14 \%$.

\section{Keanekaragaman Jenis}

Keragaman jenis adalah sifat komunitas yang memperlihatkan tingkat keanekaragaman jenis organisme yang ada didalmnya. Untuk memperoleh keanekaragaman jenis ini cukup diperlukan kemampuan mengenal dan membedakan jenis meskipun tidak mengidentifikasi jenis hama (Krebs, 1978).

Tingkat keanekaragaman jenis serangga secara umum memiliki Indeks Shannon - Wienner yang rendah dapat di lihat pada table 5. di bawah ini

Indeks Shannon - Wienner

Tabel 5. Data dan hasil perhitungan nilai indeks keanekaragaman (H), indeks kemerataan (E).

\begin{tabular}{clcccc}
\hline No & \multicolumn{1}{c}{ Nama Jenis } & Famili & Ind & $\mathrm{H}^{\prime}$ & $\mathrm{E}$ \\
\hline 1. & Belalang Kayu & Acrididae & 11 & 0.34 & 0.13 \\
2. & Belalang kaki panjang & Grillidae & 6 & 0.26 & 0.10 \\
3. & Congcorang & Mantidae & 1 & 0.08 & 0.03 \\
4. & Lebah Belang & Vespidae & 1 & 0.08 & 0.03 \\
5. & Kupu - kupu putih & Pieridae & 2 & 0.13 & 0.05 \\
6. & Capung & Libellulidae & 2 & 0.13 & 0.05 \\
7. & Kupu - kupu kuning & Pieridae & 1 & 0.08 & 0.03 \\
8. & Kumbang merah & Coccinellidae & 1 & 0.08 & 0.03 \\
9. & Kungkang & Alydidae & 4 & 0.21 & 0.08 \\
10. & Kumbang tanah & Carabidae & 3 & 0.17 & 0.07 \\
11. & Nyamuk Hijau & Chironomida & 3 & 0.17 & 0.07 \\
12. & Rambetuk & Drosophilidae & 9 & 0.31 & 0.12 \\
13. & Ngengat & Prebidae & 3 & 0.17 & 0.07 \\
14 & $\quad$ Semut bersayap & Farmicidae & 1 & 0.08 & 0.03 \\
& & & & 2,31 & 0,87 \\
\hline
\end{tabular}

Tabel 6. Data dan hasil perhitungan nilai Indeks Shannon-Winner

Sawah

\begin{tabular}{llllcc}
\hline No & \multicolumn{1}{c}{ Nama } & \multicolumn{1}{c}{ Ordo } & \multicolumn{1}{c}{ Family } & I Ind & H' \\
\hline 1. & Belalang Kayu & Orthoptera & Acrididae & 7 & 0.35 \\
2. & Belalang Kaki Panjang & Orthoptera & Grillidae & 5 & 0.32 \\
3. & Capung & Odonata & Libellulidae & 2 & 0.20 \\
4. & Kungkang & Hemiptera & Alydidae & 4 & 0.29
\end{tabular}




\begin{tabular}{llllll} 
5. & Kumbang Tanah & Coleoptera & Carabidae & 3 & 0.25 \\
6. & Nyamuk Hijau & Diptera & Chironomida & 1 & 0.13 \\
7. & Rambetuk & Diptera & Drosophilidae & 2 & 0.20 \\
8. & Ngengat & Lepidoptera & Prebidae & 1 & 0.13 \\
9. & Semut Bersayap & Lepidoptera & Farmicidae & 1 & 0.13 \\
\hline
\end{tabular}

Tabel 7. Data dan hasil perhitungan nilai Indeks Shannon-Winner Hutan Campuran

\begin{tabular}{llllcc}
\hline No & \multicolumn{1}{c}{ Nama } & \multicolumn{1}{c}{ Ordo } & \multicolumn{1}{c}{ Family } & Ind & H' \\
\hline 1. & Belalang Kayu & Orthoptera & Acrididae & 4 & 0.31 \\
2. & Belalang Kaki Panjang & Orthoptera & Gryllidae & 1 & 0.14 \\
3. & Congcorang & Mentodea & Mantidae & 1 & 0.14 \\
4. & Lebah Belang & Hymenoptera & Vespidae & 1 & 0.14 \\
5. & Kupu-Kupu Putih & Lepideptora & Pieridae & 2 & 0.22 \\
6. & Kupu-Kupu Kuning & Lepideptora & Pieridae & 1 & 0.14 \\
7. & Kumbang Merah & Coleoptera & Coccinellidae & 1 & 0.14 \\
8. & Nyamuk Hijau & Diptera & Culicidae & 2 & 0.22 \\
9. & Rambetuk & Diptera & Drosophilidae & 7 & 0.36 \\
10. & Ngengat & Erebidae & Pribidae & 2 & 0.22 \\
\hline
\end{tabular}

Dengan nilai keanekaragaman pada sestiap lokasi (habitat sawah keanekragaman paling tinggi jenis Phlaeoba Fumosa H'=0,35 dan pada habitat hutan campuran keanekaragaman paling tinggi jenis Drosophila Melanogaster $\mathrm{H}^{\prime}=0,36$ ). Menurut Odum (1998), apabila ndeks keseragaman mendekati satu, maka organisme pada komunitas tersebut menunjukkan keseragaman, sebaliknya bila indeks keseragaman mendekati nol, maka organisme pada komunitas tersebut tidak seragam. Di perkuat dengan pernyataan Michael (1995) kisaran nilai $\mathrm{H}^{\prime}>1$ berarti keanekaragaman rendah nilai indeks keragaman kurang dari 1 yang hanya berkisar antara $0,14-0,36$ maka tingkat keanekaragaman jenis serangga di masing-masing lokasi penelitian masih tergolong rendah.

a. Indeks Kemerataan

Nilai kemerataan jenis serangga dari dua lokasi penelitian di lingkungan hutan bungkirit dapat dilihat pada tabel 3.8 dibawah ini :

Tabel 8. Data dan hasil perhitungan nilai Indeks Kemerataan

\begin{tabular}{cccccc}
\multicolumn{5}{c}{ Sawah } \\
\hline No & Nama & Ordo & Family & $\sum$ Ind & E \\
\hline 1. & Belalang Kayu & Orthoptera & Acrididae & 7 & 0.16 \\
2. & Belalang Kaki Panjang & Orthoptera & Grillidae & 5 & 0.14 \\
3. & Capung & Odonata & Libellulidae & 2 & 0.09 \\
4. & Kungkang & Hemiptera & Alydidae & 4 & 0.13 \\
5. & Kumbang Tanah & Coleoptera & Carabidae & 3 & 0.11 \\
6. & Nyamuk Hijau & Diptera & Chironomida & 1 & 0.06 \\
7. & Rambetuk & Diptera & Drosophilidae & 2 & 0.09 \\
8. & Ngengat & Lepidoptera & Prebidae & 1 & 0.06 \\
9. & Semut Bersayap & Lepidoptera & Farmicidae & 1 & 0.06 \\
\hline
\end{tabular}

Tabel 9. Data dan hasil perhitungan nilai Indeks Kemerataan Hutan Campuran

\begin{tabular}{cccccc}
\hline No & Nama & Ordo & Family & $\sum$ Ind & E \\
\hline 1. & Belalang Kayu & Orthoptera & Acrididae & 4 & 0.13 \\
2. & Belalang Kaki Panjang & Orthoptera & Gryllidae & 1 & 0.06 \\
3. & Congcorang & Mentodea & Mantidae & 1 & 0.06 \\
4. & Lebah Belang & Hymenoptera & Vespidae & 1 & 0.06
\end{tabular}




\begin{tabular}{cccccc} 
5. & Kupu-Kupu Putih & Lepideptora & Pieridae & 2 & 0.09 \\
6. & Kupu-Kupu Kuning & Lepideptora & Pieridae & 1 & 0.06 \\
7. & Kumbang Merah & Coleoptera & Coccinellidae & 1 & 0.06 \\
8. & Nyamuk Hijau & Diptera & Culicidae & 2 & 0.09 \\
9. & Rambetuk & Diptera & Drosophilidae & 7 & 0.16 \\
10. & Ngengat & Erebidae & Pribidae & 2 & 0.09 \\
\hline
\end{tabular}

Pada lokasi sawah dengan indeks kemerataan 0,90 (rendah) dan pada lokasi hutan campuran indeks kemerataan 0,88 (rendah), terlihat dari indeks kemerataan nilai tertinggi terdapat pada lokasi sawah sedangkan pada lokasi hutan campuran mendapat nilai rendah. b. Indeks Kesamaan

Hasil perhitungan indeks Sorensen untuk mengetahui kesamaan jenis serangga pada lokasi penelitian ( sawah dan hutan campuran). Hal tersebut ditunjukkan dengan adanya kesamaan tiap lokasi penelitian sebanyak $31 \%$ (sedang)

Tabel 10. Data dan hasil perhitungan nilai Indeks Kesamaan

\begin{tabular}{|c|c|c|c|c|c|c|}
\hline \multirow{2}{*}{ No } & \multirow{2}{*}{ Nama Lokal } & \multirow{2}{*}{ Nama Ilmiah } & \multicolumn{2}{|c|}{ Jumlah } & \multirow{2}{*}{$\mathrm{J}$} & \multirow{2}{*}{$S$} \\
\hline & & & $\mathrm{HB}$ & Sawah & & \\
\hline 1 & Belalang Kayu & Phlaeoba Fumosa & 4 & 7 & 5 & $31 \%$ \\
\hline 2 & Belalang Kaki Panjang & Euscyrtus Hemelytrus & 1 & 5 & 5 & $31 \%$ \\
\hline 3 & Nyamuk Hijau & Chironomidae & 2 & 2 & 5 & $31 \%$ \\
\hline 4 & Rambetuk & Drosophila Melanogaster & 7 & 1 & 5 & $31 \%$ \\
\hline 5 & Ngengat & Euproctis Chrysorrhoea & 2 & 1 & 5 & $31 \%$ \\
\hline
\end{tabular}

\section{SIMPULAN}

Dari hasil penelitian yang telah dilaksanakan terdapat 14 jenis serangga dari 12 family yaitu : Melanoplus differentialis , Atractomorpha crenulata, Mantis religiosa, Polistes Sp, Leptosianina chiorograpah, Anisoptera, Eurema sarisari, Coccinellidae, Leptocorisa acuta, Oryctes rhinoceros, Lhironomidae, Drosophila Melanogaster, Anania Stachydalis dan Polyrhachis Baltomi.

Keanekaragamn jenis serangga di Sawah memiliki nilai 1,98 (sedang) dan di hutan campuran 2,03 (sedang)..

\section{REFERENSI}

Krebs,C.J. 1978. Ecological Methodology. Harper and Row.Publisher.New York.

Magurran, A. E. 1998. Ecological Diversity and Its Maesurement. New Jersey: Princeton University Press.
Michael P.1995. Metode Ekology Untuk Penyelidikan lapangan dan Laboratorium. Terjemahan oleh Yanty. R. Koester. 1995. Universitas Indonesia Press, Jakarta.

Odum, E.P. 1997. Dasar-dasar Eklogi ,Terjemahan oleh Fundamentals of Ecology. Edisi Ketiga. Universitas Gajah Mada Press, Yogyakarta.

Philpott,S.M and I Armbrecht. 2006. Biodiversity intropical agroforests and the ecological roll of ants and an diversity in predatory funcition. Journal Compilation. Journal the royal and tomological society. 31, 369-377

Rizali. A., Buchori, D., Triwidodo,H. 2002. Keanekaragaman Serangga pada Lahan Persawahan-Tepian Hutan, Indikator untuk Kesehatan Lingkungan. hlm. 41-48 . Vol. 9, No. 2

Suin. N. M. 1997. Ekologi Hewan. Bumi Aksara, Jakarta. 